\title{
EL SISTEMA PATRIARCAL Y LAS RELACIONES HETEROSEXUALES EN BALUN CANAN, DE ROSARIO CASTELLANOS
}

\author{
POR \\ DONALD H. FRISCHMANN \\ University of Arizona
}

En una entrevista que se le hizo en 1965, Rosario Castellanos afirmó su apego a «un realismo que sea capaz de traspasar la mera apariencia y penetrar en la ley, en lo constante de las cosas». Además, a respecto de su compromiso personal como escritora, dijo: «Me siento comprometida con una realidad con la cual no estoy conforme y para la cual quiero colaborar para que, de alguna manera, cambie»"

Los que conocen la prosa de la ya desaparecida escritora mexicana reconocerán inmediatamente que ese compromiso se da en su obra en función de la situación vital de la mujer y del indio mexicano: la mujer, víctima de la tradición y de las costumbres creadas por el hombre; en fin, de una moral «feudal», válida en el siglo xvi, pero que sigue imponiéndose en el presente, a pesar de unas condiciones que son ya totalmente diferentes ${ }^{2}$; y el indio, víctima también de las estructuras mentales del hombre blanco, que se declaró su superior desde el momento de los primeros contactos hace siglos; en fin, una relación igualmente "feudal». Cabe decir que en el escalón más bajo de la jerarquía está la mujer india, sufriendo el peso doble de la victimización tradicional, tanto por motivo de su sexo como por su condición de indígena.

Las obras de Rosario Castellanos que exhiben el doble compromiso que acabamos de esbozar son: Balún Canán (1957), Ciudad Real (cuentos) (1960) y Oficio de tinieblas (1962). Como ha observado Joseph Sommers ${ }^{3}$, las primeras dos obras enfocan relaciones indio-ladinas, pero

${ }^{1}$ María Luisa Cresta de Leguizamón, «En recuerdo de Rosario Castellanos», La Palabra y el Hombre, 19 (1976), pp. 3-18.

${ }^{2}$ Ibid.

${ }^{3}$ Joseph Sommers, "Rosario Castellanos: nuevo enfoque del indio mexicano», La Palabra y el Hombre, 29 (1964), pp. 83-88. 
ponen de relieve a personajes no indios. Oficio de tinieblas toma por fondo la misma «Ciudad Real», San Cristóbal, ciudad que para su existencia depende de la población tzotzil-tzeltal, que la rodea, pero a la que desprecia y a la vez teme. Y a diferencia de las obras que la preceden, esta novela extiende los linderos humanos para abarcar un tratamiento literario total de personajes indígenas.

Casi todos los estudios existentes sobre la narrativa realista-indigenista de Castellanos enfocan el tema del conflicto entre indios y ladinos ${ }^{4}$. Sólo uno, a mi saber, se ha ocupado de analizar el papel de la mujer y las relaciones entre los sexos, sobre todo con respecto a Oficio de tinieblas. En su atinado análisis, Phyllis Rodríguez-Peralta caracteriza el tratamiento de la mujer en la prosa de la autora mexicana de la siguiente manera:

Women's existence is separate from men. They function in the subsoil of events, and in spite of the novelty in an indigenous work of their acting directly in front of the reader (rather than through the eyes of men), only one, the mystic Catalina, has any power to cause or influence events.

In this closed society of the Chiapas region, isolated from the mainstream of Mexican life, all women seem to be marginal figures, alienated from society and from each other. They encompass not only the expected victims of man's brutality, but the brutality of women to women. There are no tender relationships, not even between mothers and daughters. ... Cruelty governs society's attitude toward old maids, whose humiliation causes them to isolate themselves within their homes. ...

The ability to bear children is of prime importance to every woman ${ }^{5}$.

'Véase la bibliografía siguiente: John S. Brushwood, Mexico' in It's Novel: A Nation's Search for Identity (Austin: University of Texas Press, 1966); María Luisa Cresta de Leguizamón, "En recuerdo de Rosario Castellanos», La Palabra y el Hombre, 19 (1976), pp. 3-18; Jean Franco, A Literary History of Spain: Spanish American Literature Since Independence (New York: Barnes and Noble, 1973); también, An Introduction to Spanish American Literature (London: Cambridge University Press, 1969); Emma Godoy, «Rosario Castellanos», Abside, 39, pp. 350354; Alfonso González, «Lenguaje y protesta en Oficio de tinieblas», Revista de Estudios Hispánicos, 9, pp. 441-450; Luis Leal, Breve historia de la literatura hispanoamericana (New York: Alfred A. Knopf, 1971); Marta Portal, «Narrativa indigenista mexicana de mediados de siglo», Cuadernos Hispanoanericanos, 298, pp. 196207; Phyllis Rodrígtuez-Peralta, "Images of Women in Rosario Castellanos' Prose», Latin American Literary Review, 14, pp. 68-80; Joseph Sommers, «Rosario Castellanos: nuevo enfoque del indio mexicano», La Palabra y el Hombre, 29 (1964), pp. 83-88.

5 Phyllis Rodríguez-Peralta, «Images of Women in Rosario Castellanos' Prose», Latin American Literary Review, 1 (1977), pp. 68-80. 
(La existencia de la mujer está aparte de la del hombre. Ella funciona en el subsuelo de los acontecimientos; y a pesar de que actúe directamente delante del lector [y no a través de la óptica del hombre], rasgo peculiar a una tal obra «indígena», solamente una, la mística Catalina, tiene algún poder para motivar o influir en los eventos.

En esta sociedad hermética de la región de Chiapas, aislada de la corriente principal de la vida mexicana, todas las mujeres parecen ser figuras marginadas, enajenadas de la sociedad y de sus prójimas. Se abarca no solamente a las víctimas comunes de la brutalidad del hombre, sino también la brutalidad de la mujer hacia la mujer. No hay relaciones tiernas, ni siquiera entre madre e hija. ... La crueldad determina las actitudes de la sociedad hacia las solteronas, cuya mortificación las obliga a aislarse dentro de su casa. ...

La habilidad de dar a luz es de suma importancia para toda mujer.)

Con respecto a Balún Canán, esta crítica se limita a decir que ahí imperan básicamente las mismas perspectivas en cuanto a los personajes femeninos y a las relaciones entre éstos y los masculinos. Sin embargo, no olvidemos que, cronológicamente, Balún Canán precede a Oficio de tinieblas, y por eso las características de la primera obra deben considerarse como antecedentes de la segunda. Empero, Rodríguez-Peralta opina que Balún Canán es menos eficaz (less effective) que Oficio de tinieblas, aunque agrega nuevas facetas a las imágenes de la mujer ${ }^{6}$.

Será nuestro propósito examinar la figura de la mujer en Balún Canán, sobre todo, pero no exclusivamente, en su función como esposa o amante, haciendo hincapié en las relaciones entre tres parejas: primero, César y Zoraida Arguiello, terratenientes de la zona indígena de Chactajal y padres de la narradora-niña, quien se encarga de relatar dos tercios de la novela; segundo, Felipe Carranza Pech, líder tzotzil del movimiento indígena, que reclama la devolución de sus tierras ancestrales, y su mujer Juana; tercero, Ernesto Arguiello, sobrino bastardo de César, contratado como maestro en la finca del tío, y Matilde Argüello, prima hermana, huérfana de César, quien viene a pasar una temporada con la familia en la finca.

Cabe decir que las tres parejas que aparecen en Balún Canán representan lo que pudiéramos llamar tres puntos separados en el espectro social de este pueblo de provincia: César y Zoraida pertenecen a la clase de latifundistas que, históricamente, ha sido la más poderosa, pero cuyo prestigio empieza a ponerse en crisis debido a la reciente legislación proindígena del gobierno de Lázaro Cárdenas; al otro extremo, Felipe Pech

${ }^{6}$ Ibid. 
y Juana, representando a la clase indígena, que históricamente ha sido la más explotada, oprimida y despreciada por los blancos, que han gozado de todo el poder político y económico, y por en medio están Ernesto Argüello, cuyo estigma social de haber nacido bastardo ha creado en él un profundo sentimiento de inferioridad ante los demás blancos, y Matilde, cuya infancia de huérfana, junto con otras circunstancias, han producido en ella problemas psicológicos que la han condenado a una vida desconsolada de soltera. En fin, son dos personas para las cuales no hay cabida en la sociedad que lo es todo para aquellos que llevan un apellido de prestigio, lo que constituye, efectivamente, el nombre de Argiiello en la comarca de Comitán.

\section{César y Zoraida Argüello}

En uno de los primeros capítulos, César le explica su modo de comportamiento sexual al joven Ernesto, e insta a su sobrino a que se sirva libremente de las doncellas indígenas que viven en sus propiedades. La cuestión de las relaciones degradadas entre las dos razas se resume en el siguiente razonamiento de César:

Les había hecho un favor. Las indias eran más codiciadas después. Podrían casarse a su gusto. El indio siempre veía en la mujer la virtud que le había gustado al patrón. Y los hijos eran de los que se apegaban a la casa grande y de los que servían con fidelidad.

\section{Además, su esposa Zoraida}

habría necesitado ser estúpida para ignorar un hecho tan evidente. Además, toda mujer de ranchero se atiene a que su marido es el semental mayor de la finca. ... Por lo demás no había motivo de enojo. Hijos como ésos, mujeres como ésas no significan nada. Lo legal es lo único que cuenta?.

El narrador, haciéndonos parte de los sentimientos interiores del señor de la finca, César, establece así los rasgos más notables no sólo de este individuo, sino de toda la sociedad patriarcal que representa y cuyas costumbres va perpetuando sin sentirse moralmente culpable por razón ninguna.

${ }^{7}$ Rosario Castellanos, Batún Canán (México, D. F.: Fondo de Cultura Económica, 1957), pp. 80-81. Toda referencia subsecuente a esta edición se dará en el texto principal entre paréntesis. 
Zoraida, si bien pertenece a esta clase por matrimonio, proviene de las clases populares. En un largo monólogo interior nos enteramos de sus. raíces humildes:

Mamá enviudó cuando tenía cinco años. ¡Qué trabajos pasó para criarme! Haciendo sombreros de palma, camisas de manta para los. burreros. Todo el día nos quebraban la puerta los que venían a cobrar. ... Por eso cuando César se fijó en mí y habló con mamá porque tenía buenas intenciones vi el cielo abierto. ... Pero me daba miedo casarme con un señor tan alto, tan formal (pp. 89-91).

Sin embargo, se llevó a cabo el matrimonio, el que evidentemente para Zoraida era más que nada una forma de arribismo social; y en su condición de "gallina comprada», con los años vino el desengaño:

Me sequé de vivir con un señor tan reconcentrado y tan serio que parece un santo entierro. Como es mayor que yo, me impone. Hasta me dan ganas de tratarlo de usted. ... Para que yo deje que se me acerque todavía me tiene que rogar. No sé cómo hay mujeres tan locas que se casan nomás por su necesidad de hombre (p. 92).

Además, las diferencias intelectuales han puesto una barrera más entre los dos:

Se aburre conmigo porque no sé platicar. Como él se educó en el extranjero. Cuando éramos novios ... nunca lo entendí. Ahora casi no habla conmigo. No quiero ser una separada como Romelia. Se arrima uno a todas partes y no tiene cabida con nadie. Si se arregla uno, si sale a la calle, dicen que es uno una bisbirinda. Si se encierra uno piensan que a hacer mañosadas. Gracias a Dios tengo mis dos hijos. Y uno es varón (p. 92).

A través de este monólogo tan revelador, el narrador nos hace saber varios hechos que serán aplicables a todo un sector de la población; a saber: las mujeres que sienten la necesidad de casarse por razones económicas o sociales, o por miedo de morirse de hambre, o por temor de convertirse en solteronas, una forma vergonzosa de muerte en vida. Sin embargo, una vez que la mujer, como Zoraida, se da cuenta de las implicaciones cabales de su nueva vida (sobre todo si el marido es uno de los finqueros típicos al estilo de César), el mismo miedo que la llevó a la vida de casada la impide dejarla; y si tiene niños, éstos se convierten en su único consuelo. Pero si todavía no ha nacido un varón, o si la unión ha resultado estéril, la mujer tiene harta causa de alarma, ya que no ha cumplido con su «obligación» como esposa. 
En relación -con este último punto, quisiera trasiladar nuestro análisis al otro extremo del espectro humano para enfocar a la pareja indígena, Felipe Carranza Pech y su esposa, Juana.

\section{Felipe Carranza Pech y Juana}

Juana vive en un estado continuo de tensión debido a la falta total de hijos que ha caracterizado su vida con Felipe. Por medio de un monólogo interior inicial, el narrador nos da a saber, a través de la indígena, que

Juana no tuvo hijos. Porque un brujo le había secado el vientre. Era en balde que macerara las hierbas que le aconsejaban las mujeres y que bebiera su infusión. En balde que fuera, ciertas noches del mes, a abrazarse a la ceiba de la majada. El oprobio había caído sobre ella. Pero a pesar de todo Felipe no había querido separarse (p. 108).

Por medio de esta última frase podemos intuir que, bajo tales circunstancias, el indio podía reclamar la separación. Pero, evidentemente, existe entre ellos algún lazo que los une, a pesar de que su unión no ha dado fruto todavía.

Sin embargo, Felipe se ha dado al vagabundaje. Durante una estancia como peón en Tapachula aprendió a «hablar castilla» y conoció personalmente al presidente Cárdenas, quien les presentó a los indios una copia de su manifiesto que los declaraba iguales a los blancos ante la ley y que estipulaba además que todo finquero debía proveer educación gratis a sus empleados. La reacción de Juana a las nuevas actitudes politizadas de Felipe es de temor a la soledad, además de miedo nacido de la incomprensión:

Siempre que se iba -porque era como si no tuviera raíz- ella se quedaba sentada, con las manos unidas, como si se hubiera despedido para siempre. Y Felipe volvía. Pero esta vez que volvió de Tapachula ya no era el mismo. Traía la boca llena de palabras audaces. ... Temía a este hombre que le había devuelto la costa, amargo y áspero como la sal, perturbador, inquieto como el viento. $\mathrm{Y}$ en lo profundo de su corazón, en ese sitio hasta donde no baja el pensamiento, ella deseaba que se marchara otra vez. Lejos. Lejos. Y que no regresara nunca (p. 108).

En este pasaje, Juana se muestra más pasiva y más tradicional que Felipe, en el sentido de que está dispuesta, igual que muchos de los hombres de la tribu,' a seguir aceptando como destino su situación social inferior a la de los blancos. En ella se han acumulado los siglos de opresión 
que han sufrido los indios de Chiapas, porque antes que esclavos de los españoles eran esclavos de otros indios ${ }^{8}$. En cambio, su marido, quien ha podido abrirse más al mundo precisamente por la mayor libertad permitida al macho, ha podido correr mundo, $y$ en tal proceso se ha puesto en contacto con nuevas ideas, que ni siquiera han podido conocer muchos de los otros hombres indios:

Felipe no podía tener confianza en los hombres que había escogido. La primera vez que habló con ellos, a su regreso de Tapachula, los encontró inconformes, próximos a la rebeldía, pero andaban aún, como él antes de su viaje, en tinieblas. Y no para consolar, no para mentir, les contó lo que había visto. Y una vez y otra vez tuvo que repetirlo para quebrar su desconfianza. No había que esperar la resurrección de sus dioses (p. 106).

Más adelante, en otro monólogo interior, conocemos aún más plenamente la personalidad de Juana, y en él se subrayan todavía más las diferencias entre ella, en su papel de representante de la mujer indígena, y Felipe, en el suyo de líder de un movimiento que él tiene por necesario:

Juana no alcanzaba a entenderlo y se golpeaba la cabeza con los puños, preguntándose qué estaba pagando para ser castigada de este modo.

Juana no veía más salida a su situación que ir a la casa grande y decir todo lo que estaba haciendo Felipe para que los patrones le hicieran el favor de considerar si éste era un caso de brujería y cómo había que curarlo. Porque no. ... Felipe era un malagradecido. En vez de rendirles a los patrones, como era su obligación, ¿qué hacía? Pasarse el día entero metido en el monte. Metido de puro haragán (p. 180).

Lo que Juana no logra entender es cómo Felipe ha podido romper con las relaciones tradicionales patrón-peón. Además, cree que su labor diurna, organizadora, en el monte es un pretexto por no trabajar. Pero lo que le duele más es el hecho de que Felipe se ha entregado por completo a su tarea agrarista, y que al fin y al cabo lo han apoyado muchos de los otros:

Eran los otros que lo soliviantaban con el respeto que le mostraban. Lo dice Felipe. Y se iban corriendo a obedecerlo. No lo dejaban sosegar ni un rato en su casa, con su familia, con ella que era toda su familia. Bueno. Ella tampoco quería que Felipe estuviera allí. Porque cuando

${ }^{8}$ Cresta de Leguizamón. 
estaba era sólo para mostrar las malas caras, el ceño de la preocupación.

No voy a aguantar más, dijo Juana. Me voy a ir con los patrones cuando se vayan a Comitán. Voy a ser la salera. Voy a hablar castilla delante de las visitas. Sí, señor. Sí, señora. Y ya no voy a usar tzec (p. 180).

Podemos trazar un paralelo entre la mujer blanca pobre, representada por Zoraida previo a su casamiento, y la mujer indígena, representada por Juana, en cuanto a la única manera de arribismo social que parecen tener a su alcance: arrimarse al rico. En los dos casos, tal solución también implica una renuncia, no a la libertad personal, ya que eso es algo que la sociedad blanca o india apenas reconoce como derecho de la mujer; pero sí de las raíces en que se ha criado. La madre de Zoraida la tiene por «gallina comprada»; y la india que deja la tribu para vivir entre los blancos puede esperar que su renuncia sea vengada por medio de la brujería, de la que la nana de la narradora-niña cree estar sufriendo porque «es malo querer a los que mandan, a los que poseen. Así dice la ley» (p. 16).

En los dos casos, el narrador está demostrando claramente la esclavitud común a la mujer de las clases populares y a la indígena. Para alcanzar un grado mayor de comodidad material hay que venderse. Pero, a pesar de los logros materiales, Zoraida sigue más infeliz que nunca, y la nana tiene que aguantar al mismo tiempo los castigos crueles de Zoraida y el miedo a las represalias de los brujos tzotziles. A pesar de su condición algo paralela, no puede haber identificación entre las dos como mujer, porque entre ellas existen las barreras de raza y de clase, creadas desde el principio por la sociedad patriarcal, encabezada por los hombres. para garantizar su hegemonía total: de sexo, de raza y de clase.

En esto se cumple la observación antes citada respecto a la brutalidad de mujer a mujer en la prosa de Rosario Castellanos, además de la comúnmente observada violencia de hombre a mujer. Basándonos en este comentario, nos parece conveniente pasar al análisis de la tercera mujer que ocupa un lugar destacado en Balún Canán, la huérfana Matilde, y su relación con su consorte inesperado, el bastardo Ernesto. Ambos personajes han pasado por experiencias poco felices, y el contacto que se lleva a cabo entre ellos sólo conduce al odio y la incomprensión, productos de la falta de práctica vital que caracteriza a los dos. 


\section{iII. ERnesto y Matilde Argüello}

Matilde, prima hermana de César, se caracteriza por su extrema timidez. Criada desde niña por su hermana mayor, Francisca, vivió casi toda su vida en el rancho familiar, apartada de la sociedad en que su familia tenía sus raíces. Al morir su padre, Francisca abandonó a su novio para entregarse al trabajo de la finca y a la cría de su hermana. A Francisca no le da miedo la posibilidad de una insurrección indígena, pero a fin de cuentas lo único que le permite seguir en su tierra es su vuelta a la brujería, de tal modo ganándose de nuevo el respeto perdido de los indios; pero, en el proceso, contribuyendo a la crisis nerviosa de la ya frágil Matilde.

La más joven de tres hermanas, Matilde, nunca quiso casarse por apego a su hermana mayor. Además, pasó su niñez en la tristeza que, por lo menos parcialmente, le fue impuesta por otros como requisito de su condición:

Es muy triste ser huérfana. ¿Cuántas veces se lo dijeron a Matilde acariciando su cabeza como con lástima! Esta niña se va a criar a la buena de Dios, igual que el zacate. Porque Francisca, la segunda madre, es muy joven todavía, se casará. Y la criatura vendrá a ser como un estorbo. ¿Y si Francisca no se casa? Peor. En esta familia no habrá un respeto de hombre.

Matilde se iba, cabizbaja, con una palabra zumbando a su alrededor. Huérfana. Las visitas eran malas. Le decían eso porque creían que estaba sola, que no tenía a nadie (p. 118).

En tales momentos de abyección, Matilde se refugia en un armario, sintiéndose «bien protegida por aquel regazo oscuro» que le proporciona la ropa que todavía queda allí de su difunta madre. Como sugiere el pasaje citado, no es tanto la falta de los padres como los prejuicios de los demás lo que provoca en Matilde sus temores y su estado de nerviosidad. Sin embargo, su aislamiento la lleva a fantasear con un novio ideal:

Le gustaba acostarse en la hamaca el día entero y estarse allí, pensando. (Era siempre en una fiesta. Matilde estaba sentada bajo una lámpara de cristal. El ruedo de su vestido se derramaba a su alrededor y ella tenía una copa en la mano. Había música. Una orquesta tocaba un vals y las parejas bailaban. Matilde tenía los ojos bajos, por modestia. Alguien la había elegido desde lejos y venía a invitarla a bailar. Ella veía primero sus pies, calzados de charol. Y luego el traje de casimir fino y la camisa blanca y el nudo de la corbata bien hecho. $Y$ cuando 
iba a verle el rostro, un grito, el aletear de los gavilanes rondando el gallinero, una puerta cerrada por un golpe de viento, algo, la despertaba. El rostro de ese hombre - el que iba a llegar, al que estaba destinada- se le ocultó siempre como se le había ocultado el rostro de su madre) (p. 119).

Sea porque Matilde nunca conoció a ningún hombre que llenara los requisitos de elegancia que ella establecía para su amante fantástico, o bien porque la posibilidad de encontrarse realmente en la situación fantaseada le parecía demasiado remota, la identidad del novio imaginario nunca se le revela. Lo único que queda patente es su elegancia y el elevado rango social que ésta lleva implícita en st sociedad.

Ernesto, sobrino de César, es un bastardo resentido cuyo profundo sentido de inferioridad rige todas sus acciones. En el viaje con sus tíos y primos a la finca familiar, donde desempeñará el cargo de maestro rural, hace escala con ellos en Palo María, la finca ganadera de las tres primas hermanas de César: «Tía Romelia, la separada, que se encierra en su cuarto cada vez que tiene jaqueca. Tía Matilde, soltera, que se ruboriza cuando saluda. Y tía Francisca» (p. 69) ${ }^{9}$.

Al entrar la familia Argüello en la casa, ocurre la siguiente escena, que pone en relieve los temperamentos tanto de Ernesto como de Matilde:

Nos sentamos todos en el corredor y tomamos un vaso de temperante.

-Nos da mucho gusto tenerlos entre nosotros — dice tía Matilde mirando especialmente a Ernesto.

...

- ¿Ya terminó, señor?

Tía Matilde recibe el vaso de Ernesto.

-No le digas señor. Es tu sobrino. El hijo de mi hermano Ernesto. - ¿De verdad?

Tía Matilde no sabe ocultar su contrariedad. Interviene tía Francisca.

- Me alegra saber que eres de la familia.

- ¿Aunque no sea yo más que un bastardo?

La voz de Ernesto es desafiante y dura. Tía Matilde enrojece y deja caer el vaso al suelo. Echa a correr hacia el interior de la casa, cubriéndose el rostro con el delantal (p. 70).

9 Esta descripción escueta es la única que nos entrega la narradora-niña en referencia a sus tías; en general, no se nos describe el aspecto físico de los personajes de la novela. 
El comportamiento inesperado de estos dos personajes sirve para separarlos emotivamente desde un principio: Ernesto cree que su condición de bastardo debe colocarse por encima de todo, y no tiene pelos en la lengua para hacerlo saber en cualquier momento, y Matilde no aguanta cualquier situación que resulte algo embarazosa, aunque no sea ella la directamente afectada. Sin embargo, podemos vislumbrar en su reacción una esperanza inicial, rápidamente desplomada por la declaración franca del joven, cuya presencia le parece agradar hasta que él, chocantemente, se declara indigno de cualquier atención.

Respecto a la edad de Matilde, Francisca dice de sobremesa que, «en cuanto a Matilde, todavía no es propiamente una vieja. ¿No te parece, Ernesto? Tía Francisca no obtuvo respuesta. Continuó: - Debe divertirse un poco» (p. 71). Sabemos, por tanto, que no es ni joven ni vieja. En cuanto a Ernesto, no sabemos tampoco qué edad tiene, pero se puede deducir que es algo menor que Matilde, lo cual pondría un estorbo más a su relación, dadas las normas establecidas por la sociedad, según las cuales la mujer no debe exceder en años a su consorte.

Con todo, el hecho principal que determina los resultados trágicos del encuentro entre Ernesto y Matilde es la manera poco respetuosa en que Ernesto la seduce. Sin prever las consecuencias de su acto, una tarde Matilde intenta meter a escondidas un manojo de hierbas debajo de la almohada de Ernesto, pero éste la sorprende y llega a la conclusión, probablemente certera, de que ella lo quiere conquistar por medio de un filtro amoroso. En el diálogo que sigue, Ernesto muestra su poco tacto con las mujeres:

- ¿Por qué inventó usted esa mentira?

$\cdots$

-Que usted vino a Chactajal huyendo de su hermana. Usted no vino huyendo de nadie. Usted vino buscándome a mí (p. 122).

Llegan los dos a discutir, Matilde en la ofensiva y Ernesto apenas en la defensa de la dignidad que no cree poseer como bastardo: "Nací marcado. No tengo delito, pero nací marcado» (p. 123).

Para contener los avances ya físicos de Ernesto, Matilde le grita: «¿No te das cuenta? Mírame, mírame bien. Estas arrugas. Soy vieja, Ernesto. Podría ser tu madre» (p. 124). Pero Ernesto la alcanza antes de que llegue a la puerta:

Los labios de Ernesto se posaron en su mejilla y fueron borrando las arrugas, una por una. Volvió a ser joven como antes. Como cuando se sentaba bajo la lámpara de cristal, sosteniendo una copa entre su 
mano. Amortiguados por la música de la orquesta se acercaban los pasos. Miró primero los zapatos. Eran viejos. Los pantalones, remendados; el cuello de la camisa abierta, sin corbata. Y por fin el rostro, el rostro de Ernesto. Su mano soltó la copa, que fue a estrellarse contra el suelo (p. 125).

En este momento Matilde se introduce a lo que hubiera podido ser para ella el primer amor; pero, por el contraste violento entre la elegancia del amante imaginado y la aspereza brutal de Ernesto, aunada a la experiencia espantosa de ver a su hermana Francisca convertida en bruja, y como consecuencia, la de ser obligada a huir de su propia casa, la vida de Matilde será de ahí en adelante una constante evasión de la realidad, que la lleva a intentar el suicidio (a pesar de que Ernesto ahora responde con aparente cariño a su hermética frialdad) por lo asqueada que está por el contacto físico con Ernesto y por la seguridad de que «él tenía que despreciarla por lo que pasó» (p. 142). Al mismo tiempo, sin embargo, ella sigue sintiendo un extraño cariño hacia él, aunque le dan remordimientos por su conducta y por sus malos pensamientos:

Y los ojos de Matilde se llenaron de lágrimas. Hubiera querido correr y alcanzar a Ernesto y humillarse a sus pies y besárselos como para pedir perdón por aquellos pensamientos tan ruines.

(Si yo dispusiera de dinero, como antes, iría corriendo a la tienda y le compraría todo, todo. ¿Qué cara alegre pondría!...) (p. 154).

Sin embargo, su conciencia de ser «vieja», y por eso seguramente despreciada por Ernesto, le imposibilita cualquier tentativa de reconciliación por su parte.

El «aparente cariño» de Ernesto hacia Matilde se manifiesta claramente cuando ella es salvada en su malogrado intento de suicidarse en el río; Ernesto la viene a animar con caricias y palabras tiernas, las que ella rechaza en cuanto recupera el sentido:

- ¿Por qué no me dejaron morir?

Su voz sonaba fría, rencorosa. Ernesto quedó atónito, sin saber qué contestar. No esperaba esta pregunta. Se puso de pie y desde su altura dejó caer las palabras como gotas derretidas de plomo.

- ¿Querías morir?

Matilde se había incorporado y respondió con vehemencia:

-iSí!

$\mathrm{Y}$ ante el gesto de estupefacción de Ernesto:

- iNo seas tan tonto de creer que fue un accidente! Sé nadar, conozco estos ríos mejor que el kerem que me salvó. 
-Entonces tú...

-Yo. Porque no quiero que nazca este hijo tuyo. Porque no quiero tener un bastardo.

Retadora, sostuvo la mirada de Ernesto. Y vio cómo su propia imagen iba deformándose dentro de aquellas pulilas hasta convertirse en un ser rastrero y vil del que los demás se apartan con asco.

- ¿Por qué no te atreves a pegarme? ¿Tienes miedo?

Pero Ernesto se dio vuelta lentamente y echó a andar. Matilde respiraba con agitación (pp. 159-160).

Con el tiempo, Matilde, secretamente, logra abortar el niño con la ayuda de Amantina la curandera. Sólo lo sabe Ernesto, y a causa de ello se abandona al trago, provocando una crisis entre los indios, a quienes sirve como maestro, y porque César se niega a contratar a otro en su lugar. Los indios se vengan de su intransigencia prendiendo fuego a la finca, y César decide que la única solución será enviar a Ernesto con una petición de ayuda al presidente municipal de Ocosingo. Ernesto acepta el encargo, esperando redimirse ante los otros en el proceso:

¡Con qué gusto los verían llegar a Chactajal! El, Ernesto, les había salvado la vida. Y Matilde lo miraría otra vez con los mismos ojos ávidos con que lo vio llegar a Palo María, antes de que las palabras de César le hicieran saber que era un bastardo. Pero ahora, con ese acto de generosidad, iba a convencerlos a todos de que su condición de bastardo no le impedía ser moralmente igual a ellos o mejor (p. 213).

Pero Ernesto es muerto por los indios antes de llegar y su cadáver es devuelto a la finca atado a su caballo. Al verlo llegar, Matilde se lanza a besarle las mejillas y el cabello gritando: «iYo lo maté! iYo fui su querida! ¡Yo no dejé que naciera su hijo!... Pregúntale a doña Amantina cómo me curó. Yo he deshonrado esta casa y el apellido de Argüello» (p. 216). César le contesta diciendo simplemente: «Vete.» Luego ella besa a Ernesto por última vez y se echa a andar para perderse en la montaña. «Nadie siguió su rastro. Nadie supo dónde se perdió» (p. 217).

Este episodio del extraño amor entre dos seres marginados por la sociedad pone de manifiesto, igual que en los dos casos ya examinados, una serie de consecuencias desastrosas que pueden resultar de la moral, de la tradición y de los prejuicios pervertidos de la sociedad patriarcal en la cual les toca vivir. Su destino fatal es determinado mayormente por voluntades ajenas que no dejan lugar al albedrío, ya que éste podría poner en crisis el rígido sistema de normas sociales y morales que ha regido la conducta humana en su pueblo desde tiempo inmemorial. 
Para resumir, es la fuerza de esa tradición, cuyo valor apenas se cuestiona, lo que provoca un estado de melancolía y a veces la desgracia en gran número de los personajes de la prosa novelesca de Rosario Castellanos, y la víctima en la mayoría de los casos es o el indígena o la mujer: Zoraida, cuyas esperanzas de arribismo social la han colocado al lado de un hombre tan diferente de ella que no hay posibilidad de comunión alguna entre las dos almas unidas por el lazo del matrimonio; Juana, cuya ignorancia y apego a la tradición le impide ver el mérito de la labor de su esposo, ya que las ausencias prolongadas de éste, tanto como su conducta indiferente hacia su esposa, no dejan lugar a que Juana lo intente comprender siquiera; y, en cambio, ella espera encontrar la felicidad sirviendo en la casa de los Arguiello en Comitán. Finalmente, la soltera Matilde, cuya condición de huérfana la ha apartado de la gente (salvo aquellos que le pronosticaban una vida de tristeza), preparándola muy poco para una posible relación heterosexual y sumiéndola en un estado de abatimiento emocional que la lleva dos veces a intentar el suicidio, posiblemente logrando su propósito al final, ya que su primo César efectivamente la echa de la casa por haberla deshonrado.

Así pinta Rosario Castellanos la realidad de su región natal de Chiapas, con la cual la autora sintió el compromiso de ayudar a transformarla a través de la literatura, vista por ella como arma de lucha social. Sin embargo, gracias a sus rasgos más universales, sobre todo en lo que toca a las relaciones entre los sexos, la realidad manifestada en Balún Canán franquea las fronteras del regionalismo para proyectar un mensaje a la humanidad en un sentido mucho más amplio. 